February 2019

\title{
Quality scholarship informing teaching, supervision and mentorship: The aim of Teaching and Supervision in Counseling
}

Kelly L. Wester

University of North Carolina at Greensboro

Follow this and additional works at: https://trace.tennessee.edu/tsc

Part of the Counselor Education Commons

\section{Recommended Citation}

Wester, Kelly L. (2019) "Quality scholarship informing teaching, supervision and mentorship: The aim of Teaching and Supervision in Counseling," Teaching and Supervision in Counseling: Vol. 1 : Iss. 1 , Article 1. http://doi.org/10.7290/tsc010101

Available at: https://trace.tennessee.edu/tsc/vol1/iss1/1

This article is brought to you freely and openly by Volunteer, Open-access, Library-hosted Journals (VOL Journals), published in partnership with The University of Tennessee (UT) University Libraries. This article has been accepted for inclusion in Teaching and Supervision in Counseling by an authorized editor. For more information, please visit https://trace.tennessee.edu/tsc. 


\section{Quality Scholarship Informing Teaching, Supervision, and Mentorship: The aim of Teaching and Supervision in Counseling}

\section{Kelly L. Wester}

It is with excitement that I present the inaugural issue of Teaching and Supervision in Counseling (TSC), the official journal of the Southern Association for Counselor Education and Supervision (SACES). The leaders of SACES have envisioned this journal for many years, and their vision has finally come to fruition. The aim of $T S C$ is to publish high-quality scholarship that informs teaching, supervision, and mentoring in educational and clinical settings. While this aim may sound simple, it is very complex because it comprises three factors: informing teaching, supervision, and mentoring within (a) educational settings, and (b) clinical settings through the use of (c) high-quality scholarship. So let's take a moment to break these down.

To inform aspects of an educational setting is to inform the practices occurring where counselors are trained. The primary location for this is within counselor education programs. On a day-to-day basis, counselor educators wear many hats, so to say that counselor educators simply educate is an understatement, especially considering that our role includes training future practitioners, counselor educators, supervisors, researchers, leaders, and administrators. At times, this results in counselor educators wearing an instructor hat and standing in front of a classroom providing knowledge or facilitating an experiential activity to foster the development of a skill. Other times, we serve as supervisors working in individual, triadic, or group settings with trainees on skill development, personal growth, and handling discomfort. In addition, we support students who may be struggling, applaud those who have experienced "aha" moments or success, and mentor students in various professional activities and identity development. We work with students to help them engage in research projects and learn about the research process through their dissertations and other experiences. While wearing all these hats, our goal is to spark interest, enhance knowledge, and facilitate skill development for our current students - who represent the profession's future practitioners, supervisors, counselor educators, and researchers who will continue to propel our field forward - with the goal of impacting the clients and public who will seek and receive our services.

Therefore, with the manuscripts we accept and publish in TSC, we aim to inform the counselor educators and supervisors training our

Kelly L. Wester, PhD, University of North Carolina at Greensboro 
next generation of counselors. This can include information on what we train, how effective we are at training, and what methods produce the best outcomes. Very little attention has been given to exploring pedagogical practices and teaching and learning outcomes (Barrio Minton, Wachter Morris, \& Bruner, 2018; Barrio Minton, Wachter Morris, \& Yaites, 2010). While articles focused on pedagogical practices doubled from 2010 to 2018 , only $21 \%$ of articles focused on these practices. As an example of the lack of focus on pedagogy and teaching practices, Bernard and Luke (2015) highlighted that while we focus on how to do supervision, little has been published on how to teach supervision.

Generally, most of the research conducted within the field of counseling tends to be descriptive. Content analyses of articles published within Counselor Education and Supervision (Crockett et al., 2010) and Journal of Counseling and Development (Wester, Borders, Boul \& Horton, 2013) reveal that most articles published are quantitative in nature, with quantitative articles predominantly using descriptive methodology. There is a definite value to descriptive methodology because it helps inform theory and enhance our knowledge of factors that correlate or function in tandem (Heppner, Wampold, Owen, \& Wang, 2016; Wachter Morris \& Wester, 2018); however, outcome-based knowledge and the effectiveness of our teaching/supervision methods cannot be determined via descriptive methodologies since they lack control within the design. Therefore, descriptive methodology is an important place to start, but as educators and scholars, we need to begin pushing the next level of outcome-based research with supervision and pedagogy to ask the harder questions about whether what we do in the classroom or in supervision is effective. Some authors (e.g., Paladino, Barrio Minton, \& Kern, 2011) have utilized quasi-experimental designs to explore such questions. These designs are possible, and they can be done either with single individuals, cohorts, or groups (i.e., single-case research design; Lenz, 2015) or with larger samples utilizing quasi-experimental designs or program evaluation.

This focus on outcome-based research is not solely to highlight quantitative research since quantitative research has its limitations. Qualitative research is also needed to better understand student experiences, including those that have led to effective outcomes. Thus, the ability to incorporate strong qualitative research to explore supervision and pedagogy within educational settings is also important. This can include a case study design focusing on one individual, group, or program to provide a holistic, in-depth perspective, but qualitative methodology can also include (but not be limited to) phenomenological research, consensual qualitative research, and narrative approaches. While we need quantitative research methods to answer causation and relationship-based questions to generalize to the larger student body or counselor education programs, we also need qualitative methodologies to provide a depth of understanding and viewpoints that we may not have considered a priori. Ultimately, mixed methodologies (Wester \& McKibben, in press) combining qualitative and quantitative methodologies should also be considered to inform teaching, supervision, and mentoring in our educational and clinical settings.

While most of this dialogue has focused on teaching and supervision, our vision does not exclude mentoring. We also need to better understand the impact mentoring has on our students and faculty within our programs. How do we best mentor master's or doctoral students at various stages of their education and within different tasks and activities? How do we help mentor and relationally work with students to ensure they feel accepted and included within our programs and curricula? How do we help our pre-tenured faculty effectively achieve promotion and tenure? How do we mentor new faculty (clinical, lecturing, adjunct, assistant, associate, and beyond) to effectively supervise and teach students in our programs? These questions will help inform us in the educational setting. Therefore, TSC will focus on what we are doing to effectively train, supervise, and mentor our students within our educational programs at the master's and 
doctoral levels.

What we do within the educational setting also spans to the clinical setting. The aim of TSC is to focus not on what works clinically with clients or students but more so on teaching, training, supervising, and mentoring practicing counselors in the $\mathrm{K}-12$ school, college, university, clinical mental health, and medical settings. Thus, we consider all the questions, inquiries, and methodologies noted above, but we do so while taking them out of the educational program and into the clinical setting. For example, how can supervisors within a clinical setting provide effective supervision? What is needed among supervisees who hold their LPCA licenses? How might administrators effectively train, teach, or mentor counselors within a clinical mental health setting? How can we train practicing counselors to conduct their own outcome-based research?

To achieve this aim of informing teaching, supervision, and mentorship, we need quality scholarship, which begins with idea inception and an assurance that researchers engage in ethical research (Wester, 2011). For empirical research studies, this includes following methodological design requirements, understanding the sample-size needs associated with methodologies and analyses, and accurately interpreting results. However, this also includes an ability to succinctly highlight existing literature for readers, make arguments for why a study was needed and how it adds to the literature in the literature review, and provide implications of the study findings so readers can immediately understand the potential applications of the results.

Quality scholarship also pertains to conceptual pieces. Too often, authors pull together a summary of the literature and submit it as a conceptual piece. A conceptual article needs to pull ideas together from existing literature while clearly articulating a model, framework, or idea that moves an area in the field forward by contributing something new and not just a summary of what other authors have said. For example, a description of an evolutionary method to provide supervision to new counselors, an examination of an experiential method to teach counseling theories, or a call to action to train researchers effectively at a master's level are just some topics authors may cover in conceptual articles. Authors typically have these new ideas when writing conceptual manuscripts; however, one difficulty authors face lies in articulating an idea in a way that reveals how the idea adds to or expands on what is already known.

With regard to clarity of writing, Mensh and Kording (2017) highlighted the C-C-C structure, which focuses on context, content, and conclusion. These factors map out not only across entire articles but also within each paragraph. For example, a literature review in an empirical manuscript provides context for what will be covered, including background information, theoretical frameworks, and information on the population and variables. The methods and results sections provide the content, i.e., what occurred and what was found. The discussion serves as the conclusion by describing what the information tells us, how it relates to previous literature, and what we can do with it. In conceptual manuscripts, context shows readers what is known and where gaps in our existing knowledge are, while content tells readers what the new idea is, whether it is a framework, model, or call to action. This content needs to include detail since new ideas are being put forth to fill existing gaps authors highlight in the context components of manuscripts. The conclusion covers next steps, including how the information can be applied or used in practice, future studies, or next steps.

By using the C-C-C structure for each paragraph, authors can use the first sentence of a paragraph as the topic sentence to provide a context of what the paragraph will be about. Each subsequent sentence within that paragraph represents content regarding that topic, i.e., the breadth and depth of information a reader needs to know to understand the topic. Finally, the last sentence in the paragraph is the conclusion statement, i.e., what authors want readers to take away from the text. Typically, this last sentence can offer information on a gap, critique what was done, or provide a solid summary of the main point of the 
paragraph. Consider the conclusion sentence what authors want readers to know if they happened to miss what was said.

Based on this knowledge and with the support of SACES, my associate editor, and the editorial board for this inaugural issue, I am excited to put forth an issue that meets the aim of TSC by offering three articles on aspects of teaching and pedagogy, one article on supervision, and two articles on various experiences of students. Specifically, Cavazos Velo, Fisk, and Ikonomopoulous (2019) explore Latina students' experiences with instructors' practices through phenomenological methods. Giordano, Malacara, and Agarwal (2019) describe a longitudinal study they conducted from the beginning of a class to the end of a class to assess changes in students' preferences, competence, importance, and understanding of process addictions after the implementation of a new course. Dice, Carlisle, and Byrd (2019) explore the experiences of undergraduate students being trained in an addictions class using qualitative methodology. Focusing more specifically on supervision, Trepal et al. (2019) explore supervision strategies used to support Spanish-speaking bilingual counselors through supervisor experiences. Focusing on students' experiences, Tuttle, Grimes, and Lopez (2019) explore school counseling doctoral students' experiences with career-decision making, knowing that school counselors leaving their practices to seek doctoral degrees does not occur frequently. Finally, Brown-Rice and Furr (2019) explore doctoral students' awareness and impact of peers' problems of professional competence.

This issue includes work from some amazing authors who have started and/or continued the difficult work of informing teaching, supervision, and mentoring in counseling. We have many things planned for future issues, and we look forward to many authors contributing to the success of TSC as we move forward.

\section{References}

Barrio Minton, C. A., Wachter Morris, C., \& Bruner, S. L. (2018). Pedagogy in counselor education: 2011-2015 update. Counselor Education and Supervision, 57(3), 227-236.

Barrio Minton, C. A, Wachter Morris, C. A., \& Yaites, L. D. (2010). Pedagogy in counselor education: A 10-year content analysis of journals. Counselor Education and Supervision, 53(3), 162-177.

Bernard, J. M., \& Luke, M. (2015). A content analysis of 10 years of clinical supervision articles in counseling. Counselor Education and Supervision, 54(4), 242-257.

Brown-Rice, K., \& Furr, S. (2019). Am I my peers' keeper? Problems of professional competency in doctoral students. Teaching and Supervision in Counseling, 1, 33-46.

Cavazos Velo, J., Fisk, J., \& Ikonomopoulous, J. (2019). Exploring Latina clinical mental health counseling students' perceptions of teaching practices. Teaching and Supervision in Counseling, 1, 6-18.

Crockett, S. A., Byrd, R., Erford, B. T., \& Hays, D. G. (2010). Counselor Education and Supervision golden anniversary publication pattern review: Author and article characteristics from 1985 to 2009. Counselor Education and Supervision, 50, 5-20.

Dice, T. F., Carlisle, K., \& Byrd, R. (2019). Students' perspectives of experiential learning in an addictions course. Teaching and Supervision in Counseling, 1, 60-70.

Giordano, A. L., Malacara, A., \& Agarwal, S. (2019). A process addictions course for counselor training programs. Teaching and Supervision in Counseling, 1, 47-59.

Heppner, P. P., Wampold, B. E., Owen, J., \& Wang, K. T. (2016). Research design in counseling (4th ed.). Boston, MA: Cengage. 
5Lenz, S. A. (2015). Using single-case research designs to demonstrate evidence for counseling practices. Journal of Counseling and Development, 93(4), 387-498.

Mensh, B., \& Kording, K. (2017). Ten simple rules for structuring papers. PLoS Computational Biology, 13(9), e1005619. https://doi. org/10.1371/journal.pcbi.1005619

Paladino, D., Barrio Minton, C. A., \& Kern, C. W. (2011). Interactive training model: Enhancing beginning counseling student development. Counselor Education and Supervision, 50(3), 189-206.

Trepal, H. C., Tello, A., Haiyasoso, M., Castellon, N., Garcia, J., \& Martinez-Smith, C. (2019). Supervision strategies used to support Spanish-speaking bilingual counselors. Teaching and Supervision in Counseling, 1, 19-32.

Tuttle, M., Grimes, L. E., \& Lopez, C. (2019). Career-decision making: School counselors in counselor education doctoral programs. Teaching and Supervision in Counseling, 1, 71-82.

Wachter Morris, C., \& Wester, K. L. (Eds.). (2018). Making research relevant: Applied research designs for the mental health practitioner. New York, NY: Taylor \& Francis.

Wester, K. L., \& McKibben, B. (in press). Integrating mixed methods approaches in counseling outcome research. Counseling Outcome, Research, and Evaluation.

Wester, K. L. (2011). Publishing ethical research: A step-by-step overview. Journal of Counseling and Development, 89(3), 301-307.

Wester, K. L., Borders, L. D., Boul, S., \& Horton, E. (2013). Research quality: Critique of quantitative articles in the Journal of Counseling and Development. Journal of Counseling and Development, 91(3), 280-290. 